\title{
Crescimento de cultivares de melão amarelo irrigadas com água salina ${ }^{1}$
}

\author{
Renato D. Alencar ${ }^{2}$, Francisco de Q. Porto Filho ${ }^{3}$, José F. de Medeiros ${ }^{4}$, José S. de Holanda ${ }^{5}$, \\ Vânia C. N. Porto ${ }^{6}$ \& Miguel Ferreira Neto
}

\author{
1 Parte de trabalho desenvolvido pelo primeiro autor, apresentado à ESAM para obtenção do título de Especialista em \\ Irrigação e Drenagem \\ 2 Especialista em Irrigação e Drenagem. Fone: (84) 9972-9521. E-mail: alencarenato@hotmail.com (Foto) \\ ${ }^{3}$ ENA/ESAM. CEP 59625-900, Mossoró, RN. Fone: (84) 312-2100. E-mail: porto@esam.br \\ ${ }^{4}$ ENA/ESAM. Fone: (84) 312-2100. E-mail: jfmedeir@esam.br \\ ${ }^{5}$ EMBRAPA/EMPARN. Fone: (84) 221-2341. E-mail: simplícioemparn@rn.gov.br \\ ${ }^{6}$ Mestre em Agronomia. Fone: (84) 9984-0760. E-mail: vania_porto@wvi.org \\ 7 ESALQ/USP. CEP 13418-900, Piracicaba, SP. Fone: (19) 420-6171. E-mail: ferreira@esalq.usp.br
}

Protocolo $106-1 / 8 / 2002$ - Aprovado em 13/8/2003

\begin{abstract}
Resumo: Neste trabalho, estudaram-se os efeitos de cinco níveis (N) de salinidade da água de irrigação $\left(1,51 ; 2,79 ; 3,93 ; 5,15\right.$ e $\left.7,22 \mathrm{dS} \mathrm{m}^{-1}\right)$, no desenvolvimento inicial de duas cultivares de melão amarelo (Gold mine e AF646). O cultivo foi realizado na horta do Departamento de Fitotecnia da ESAM, localizada no município de Mossoró, RN, no período de 4 de novembro a 12 de dezembro de 1998, em recipientes plásticos com capacidade para 9 L, conduzidos ao ar livre, tendo como substrato Argissolo vermelho-amarelo eutrófico abrupto do horizonte $\mathrm{Ap}_{1}$, utilizando-se o delineamento em blocos inteiramente casualizados arranjados no esquema fatorial 2x5, com três repetições. As características: peso seco da parte aérea, área foliar e salinidade média e final do solo, foram avaliadas mediante análise de variância (teste F) e estudo de regressão. As cultivares Gold mine e AF646 apresentaram comportamento semelhante quanto a tolerância à salinidade da água de irrigação, com perda de fitomassa seca da parte aérea (FSPA) de 6,8\% por aumento unitário da condutividade elétrica na água de irrigação. $\mathrm{O}$ comportamento da área foliar foi similar ao da FSPA. Observou-se efeito linear e quadrático da salinidade da água de irrigação sobre a salinidade média e final do solo, respectivamente.
\end{abstract}

Palavras-chave: irrigação, condutividade elétrica, Cucumis melo, L., salinidade

\section{Growth of yellow melon cultivars irrigated with saline water}

\begin{abstract}
The effect of five irrigation water salinity levels $(\mathrm{N}: 1.51,2.79,3.93,5.15$ and $7,22 \mathrm{dS} \mathrm{m}^{-1}$ ), on initial development of two yellow melon cultivars (Gold mine and AF646) was studied. The trial was conducted under field conditions in an orchard belonging to Department of Phytotechnic - ESAM, at Mossoró in the State of Rlo Grande do Norte, Brazil, during the period of November 4 to December 12, 1998. Plastic pots with 9 L capacity filled with Alfisol soil (horizon Ap1) were used. Experimental design was a completely randomized block in a factorial scheme, with three replications. Shoot dry matter, leaf area, mean soil salinity and final soil salinity were evaluated through variance and regression analysis. Salinity tolerance was similar for Gold mine and AF646, with a loss of $6.8 \%$ of shoot dry matter for unit increase of electrical conductivity of irrigation water. A similar behavior was observed for leaf area. Irrigation water salinity induced linear effect on mean soil salinity and quadratic effect on final soil salinity.
\end{abstract}

Key-words: irrigation, electrical conductivity, Cucumis melo L., salinity

\section{INTRODUÇÃO}

Devido à baixa precipitação e à alta taxa de evaporação, é comum a ocorrência de solos salinos e sódicos em regiões áridas e semi-áridas. A utilização esgotante das fontes de água de boa qualidade, torna necessário a procura e a utilização de fontes alternativas de água mesmo sendo, na sua grande maioria, de qualidade duvidosa, razão por que se tem aumentado a utilização de águas de qualidade inferior, principalmente na irrigação em regiões semi-áridas (Rhoades et al., 1992).

Águas salinas utilizadas na irrigação podem representar risco para a produção agrícola das culturas. Em certos casos, essas águas promovem alterações nas condições físicoquímicas que não existiam inicialmente no solo, em proporções que desfavorecem o crescimento e o desenvolvimento da maioria das culturas. Conforme Richards (1954) e Daker (1984) 
a tolerância das plantas aos sais pode ser apreciada segundo três critérios: i) capacidade para sobreviver em solos salinos, com importância em estudos ecológicos, mas com pouca significação prática no que se refere à agricultura irrigada; ii) rendimento em solos salinos, de muita utilidade do ponto de vista agronômico, principalmente quando se comparam variedades de mesma espécie e iii) rendimento relativo, comparado com o alcançado em solos não-salinos.

A salinidade pode afetar o comportamento das plantas de forma diferente, em função do seu estágio de desenvolvimento (Hebron, 1967; Shannon \& Francois, 1978). As espécies e cultivares se comportam de forma diferente à salinidade, isto é, cada espécie de planta ou cultivar tolera até certa salinidade (Salinidade limiar - SL), sem reduzir o seu rendimento potencial, a partir da qual passa a diminuir a produtividade à medida que se incrementa a salinidade do solo (Maas \& Hoffman, 1977; Rhoades \& Loveday, 1990; Medeiros, 1998). Desta forma, a definição da salinidade da água/solo crítica para a cultura explorada é fundamental para melhorar o manejo das áreas irrigadas.

Segundo Shannon \& François (1978) e Nerson \& Paris (1984) algumas variedades da cultura do melão (Cucumis melo) são moderadamente tolerantes a sais, podendo variar conforme $o$ meio de cultura à germinação, tipo de salinidade, estádio de crescimento da planta e cultivar.

Nerson \& Paris (1984) estudando o efeito da salinidade sobre quatro cultivares de melão, verificaram relação entre parâmetros medidos no desenvolvimento inicial e a produção obtida, assim como o peso seco é uma variável indicada na seleção de cultivares de melão tolerante à salinidade. Franco et al. (1997) pesquisando, na Espanha, seis híbridos do melão tipo galia (Delada, Gallicum, Golar, Melina, Regal e Revigal), verificaram que o Melina foi o mais tolerante, produzindo 66\% para a água de $7,5 \mathrm{dS} \mathrm{m}^{-1}$ em relação ao rendimento obtido com a água de 2,5 $\mathrm{dS} \mathrm{m}^{-1}$, enquanto o Delano foi o mais sensível produzindo apenas $56 \%$ nas mesmas condições. Verificaram, também, que o índice da área foliar é um bom critério na seleção de hibridicos tolerantes à salinidade, porém novos testes devem ser feitos para se avaliar a tolerância de sais nesta cultura em várias condições. Shannon \& François (1978) encontraram, para o melão, uma SL correspondente a um nível de condutividade elétrica do extrato de saturação do solo (CEes) de $1,3 \mathrm{dS} \mathrm{m}^{-1}$ e que o decréscimo no rendimento relativo por unidade de acréscimo na CEes, acima desse limite, foi de 5,9\%. Para Pizarro (1990) a SL do melão é da ordem de $2,2 \mathrm{dS} \mathrm{m}^{-1} \mathrm{e} o$ decréscimo no rendimento relativo por unidade de acréscimo na CEes, acima desse limite, se situa em torno de 7,25\%.

Assim, objetivou-se, neste trabalho, estudar o efeito de cinco níveis de salinidade de água de irrigação no desenvol- vimento e crescimento de duas cultivares de melão amarelo através da área foliar, altura de plantas e fitomassas seca e fresca da parte aérea.

\section{MATERIAL E MÉTODOS}

O experimento foi conduzido na horta do Departamento de Fitotecnia da Escola Superior de Agricultura de Mossoró - ESAM, no período de 4 de novembro a 12 de dezembro de 1998. Foram estudadas duas cultivares de melão amarelo (Gold mine e AF646). O cultivo foi realizado em vaso de plástico com capacidade para 9 L usando-se, como substrato, a camada superficial do solo, classificado como Argissolo Vermelho-amarelo eutrófico abrupto (EMBRAPA, 1999). As características do solo encontram-se na Tabela 1. Os vasos eram perfurados e providos de um sistema de drenagem em sua parte inferior, com uma camada de brita (no 1$)$ de $20 \mathrm{~mm}$ de espessura, para facilitar a drenagem e 3 telas de nylon de malha $2 \mathrm{~mm}$ entre o substrato e a brita, para evitar perda de solo. A drenagem foi feita através de um dreno no fundo do vaso, que permitia a saída (drenagem) do excesso de água de irrigação e desaguava dentro de garrafas plásticas com capacidade de 2 L. O solo foi secado ao ar, devidamente homogeneizado e colocado nos vasos, de modo a terem seus pesos ajustados para 11,86 kg (solo + brita + tela + vaso), com $10,96 \mathrm{~kg}$ de solo seco, por vaso. A umidade do solo, à capacidade de campo (CC), foi determinada através da pesagem de 12 vasos irrigados excessivamente, cobertos com plástico e após drenado por 24 horas.

Foram empregados cinco níveis de salinidade da água de irrigação verificando-se, ao longo do cultivo, as seguintes médias: $\mathrm{N}_{1}=1,51 ; \mathrm{N}_{2}=2,79 ; \mathrm{N}_{3}=3,93 ; \mathrm{N}_{4}=5,15 ; \mathrm{N}_{5}=7,22$ $\mathrm{dS} \mathrm{m}^{-1}$. Esses valores passaram a ser considerados os níveis para o fator salinidade da água de irrigação. As águas salinas foram obtidas através de misturas da água de poço profundo, do aquífero arenítico, existente no Campus da ESAM, com água do mar e fertilizantes. $O$ resultado da análise das águas utilizadas na preparação de diferentes níveis salinos, encontrase na Tabela 2.

Tabela 2. Características químicas da água do poço e do mar

\begin{tabular}{|c|c|c|c|c|c|c|c|c|c|}
\hline \multirow{2}{*}{ Água } & \multirow{2}{*}{$\mathrm{pH}$} & \multirow{2}{*}{ 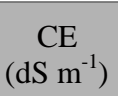 } & \multicolumn{4}{|c|}{ Cátions $\left(\mathrm{mmol}_{\mathrm{c}} \mathrm{L}^{-1}\right)$} & \multicolumn{3}{|c|}{ Ânions $\left(\mathrm{mmol}_{\mathrm{c}} \mathrm{L}^{-1}\right)$} \\
\hline & & & $\mathrm{Ca}$ & $\mathrm{Mg}$ & $\mathrm{Na}$ & $\mathrm{K}$ & $\mathrm{HCO}_{3}$ & $\mathrm{CO}_{3}$ & $\mathrm{Cl}$ \\
\hline Poço & 8,0 & 0,55 & 2,0 & 0,9 & 2,8 & 0,4 & 4,0 & 0,2 & 1,8 \\
\hline Mar & 7,4 & 56,3 & 26,8 & 86 & 502 & 25 & 2,64 & - & 614 \\
\hline
\end{tabular}

O experimento foi conduzido ao ar livre, em 3 bancadas de madeira, com $30 \mathrm{~cm}$ de altura e distanciadas $150 \mathrm{~cm}$. Em cada bancada foram colocados 12 vasos, distanciados $80 \mathrm{~cm}$, sendo que os 2 vasos das extremidades serviam de bordadura, ficando 10 vasos úteis por bancada. Para a semeadura utilizaram-se

Tabela 1. Análise física e química do solo*

\begin{tabular}{|c|c|c|c|c|c|c|c|c|c|c|c|c|c|c|c|c|c|}
\hline \multicolumn{5}{|c|}{ Física } & \multicolumn{8}{|c|}{ Fertilidade } & \multirow{2}{*}{\multicolumn{5}{|c|}{$\begin{array}{c}\text { Curva Característica - Umidade }\left(\mathrm{g} \mathrm{kg}^{-1}\right) \\
\text { Modelo do Potencial Mátrico }(\mathrm{kPa})\end{array}$}} \\
\hline \multicolumn{3}{|c|}{ Granulometria } & \multirow{2}{*}{$\mathrm{Dg}$} & $\mathrm{CC}$ & $\mathrm{Ca}$ & $\mathrm{Mg}$ & $\mathrm{Na}$ & K & $\mathrm{Al}$ & \multirow{2}{*}{$\mathrm{P}$} & \multirow{2}{*}{ PST } & \multirow{2}{*}{ CEes } & & & & & \\
\hline Areia & Silte & Argila & & $\left(\mathrm{g} \mathrm{kg}^{-1}\right)$ & & & $\mathrm{ol}_{\mathrm{c}} \mathrm{dr}$ & & & & & & 10 & 30 & 100 & 300 & 1500 \\
\hline 890 & 70 & 40 & 1,71 & 15,2 & 8,0 & 1,9 & 0,12 & 0,51 & 0 & 76,2 & 1,1 & 2,65 & 18,7 & 6,3 & 3,6 & 3,0 & 1,9 \\
\hline
\end{tabular}

Dg - Densidade global $\left(\mathrm{kg} \mathrm{dm}^{-3}\right)$; US - Umidade de saturação; CC - Capacidade de campo; P - Fósforo assimilável ( $\left.\mathrm{mg} \mathrm{kg}^{-1}\right)$; CEes - Condutividade elétrica no extrato de saturação (dS m ${ }^{-1}$; PST - Percentagem de sódio trocável 
5 sementes por vaso e, após 10 dias, realizou-se desbaste deixando-se 2 plantas por cova. Utilizou-se o delineamento experimental em blocos inteiramente casualizados, com 3 repetições, no esquema fatorial $2 \times 5$.

Antes da semeadura, colocou-se $1 \mathrm{~L}$ de água dos respectivos tratamentos, por vaso, provocando-se drenagem em todos eles. As irrigações da semeadura, até quando $66 \%$ das sementes nos vasos haviam germinado ( $8 \mathrm{~d}$ ) foram procedidas com água de poço $\left(\mathrm{CE}=0,55 \mathrm{dS} \mathrm{m}^{-1}\right)$ e na quantidade de repor diariamente apenas a evapotranspiração, determinada através de pesagens, dos 12 vasos utilizados para determinação da CC. Após este período as irrigações foram realizadas com água dos respectivos tratamentos, em quantidade suficiente para que o solo iniciasse a drenar. A água drenada era armazenada diariamente, e a cada 4-6 dias estimava-se uma lâmina de irrigação com excedente capaz de possibilitar uma fração de lixiviação (FL) de aproximadamente 0,20 , para controlar a salinidade do solo e proporcionar o fechamento do balanço hídrico em cada intervalo de dias entre as lixiviações. Após as lixiviações, os volumes drenados eram medidos e, posteriormente, analisados pela determinação da condutividade elétrica.

A fertigação foi realizada com base em Resh (1995) para a cultura do pepino utilizando-se, para todo o período, $100 \mathrm{ppm}$ de Ca, 20 ppm de $\mathrm{Mg}, 131 \mathrm{ppm}$ de N, 27 ppm de P, 175 ppm de $\mathrm{K}, 26 \mathrm{ppm}$ de $\mathrm{S}, 2 \mathrm{ppm}$ de Fe, 0,2 ppm de $\mathrm{Mn}, 0,07 \mathrm{ppm}$ de $\mathrm{Cu}$, 0,1 ppm Zn, 0,3 ppm de B, 0,03 ppm de Mo, e também as substâncias: $\mathrm{NH}_{4} \mathrm{NO}_{3}, \mathrm{FeSO}_{4} \cdot 7 \mathrm{H}_{2} \mathrm{O}, \mathrm{H}_{3} \mathrm{PO}_{4}, \mathrm{ZnSO}_{4} \cdot 6 \mathrm{H}_{2} \mathrm{O}$, $\mathrm{MnSO}_{4}, \mathrm{CuSO}_{4}, \mathrm{NH}_{4} \mathrm{MoO}_{3}, \mathrm{MgCl}_{2} \cdot 6 \mathrm{H}_{2} \mathrm{O}, \mathrm{KNO}_{3}, \mathrm{CaNO}_{3}, \mathrm{H}_{3} \mathrm{BO}_{4}$, $\mathrm{H}_{2} \mathrm{SO}_{4}$ e gesso $\left(\mathrm{CaSO}_{4} \cdot 2 \mathrm{H}_{2} \mathrm{O}\right)$.

Ao final do experimento retiraram-se amostras de solo na profundidade de $0-20 \mathrm{~cm}$, secadas ao ar, destorroadas e peneiradas em malhas de $2 \mathrm{~mm}$ e se lhes determinou a CEes, conforme Richards (1954).

Utilizando-se o balanço de sais para os intervalos entre cada lixiviação, foi estimada a salinidade do solo ao longo do tempo. A determinação do incremento da salinidade devido à água de irrigação aplicada, e o decréscimo promovido pela retirada dos sais através da lixiviação, para cada intervalo de tempo entre lixiviações, utilizando-se o balanço de sais, foram calculados através da Eq. 1 (acúmulo) e da Eq. 2 (decréscimo).

$$
\begin{aligned}
& \text { CEes }=\frac{\text { Va CEa }}{\text { Vus }} \\
& \text { CEes }=\frac{\text { Vd CEd }}{\text { Vus }}
\end{aligned}
$$

em que:

CEes - CE do extrato de saturação do solo, $\mathrm{dS} \mathrm{m}^{-1}$

$\mathrm{Va}$ - volume de água aplicada, $\mathrm{mL}$

$\mathrm{Vd}$ - volume de água drenada, $\mathrm{mL}$

Vus - volume de água no solo do vaso quando saturado, $\mathrm{mL}$

$\mathrm{CE}_{\mathrm{a}}$ - CE da água de irrigação, $\mathrm{dS} \mathrm{m}^{-1}$

$\mathrm{CE}_{\mathrm{d}}$ - $\mathrm{CE}$ da água drenada, $\mathrm{dS} \mathrm{m} \mathrm{m}^{-1}$

No final do ciclo, compararam-se os valores de salinidade medidos, em cada vaso, com aqueles estimados pelo balanço de sais. A diferença encontrada foi ponderada com os volumes de água aplicados acumulados em cada período, entre lixiviações, de modo que, no final do ciclo, o valor estimado coincidisse com o medido. A salinidade média foi obtida a partir da média ponderada pelo comprimento de cada intervalo de tempo e das salinidades médias dos respectivos períodos.

Determinou-se, aos 18, 25 e 32 dias após a semeadura (DAS), área foliar e, aos 25 e 32 DAS, altura das plantas. Na ocasião da colheita do experimento (39 DAS), as plantas de cada vaso foram cortadas rente ao solo e, em seguida, foram determinadas separadamente: área foliar, altura de plantas e fitomassa fresca das folhas, talos e frutos; depois, foram acondicionados em sacos de papel e levados à estufa a $70^{\circ} \mathrm{C}$, para secagem. As fitomassas fresca e seca da parte aérea foram determinadas pela soma das fitomassas fresca e seca das folhas, talos e frutos, respectivamente. Nas três primeiras mensurações, a área foliar foi estimada utilizando-se o cálculo da área de um círculo, cujo diâmetro foi a média entre o comprimento transversal e o longitudinal, medidos em cada folha de todas as plantas, como também a altura das plantas, computando-se a distância do nível do solo até a extremidade do ramo mais longo, com o auxílio de régua; já por ocasião da colheita, a área foliar foi determinada através do integrador de área, marca LI-COR, modelo LI-3100.

Realizou-se análise de variância dos parâmetros fitomassas seca e fresca da parte aérea, altura de planta, área foliar e salinidade média do solo. A comparação de médias foi feita pelo teste Tukey e " $t$ " $(p<0,05)$ realizando-se, também, análise de regressão para todos esses parâmetros (Gomes, 1987).

\section{RESULTADOS E DISCUSSÃO}

As curvas de salinidade do solo obtidas pelo balanço e ajustadas pelos valores de salinidade medidas no final do ciclo da cultura, encontram-se na Figura 1. Partindo-se do início do experimento ao final, observam-se aumentos graduais da salinidade do solo com reduções bruscas, em seis épocas, que corresponderam aos dias da drenagem, enfatizando-se a importância do uso dessa prática.

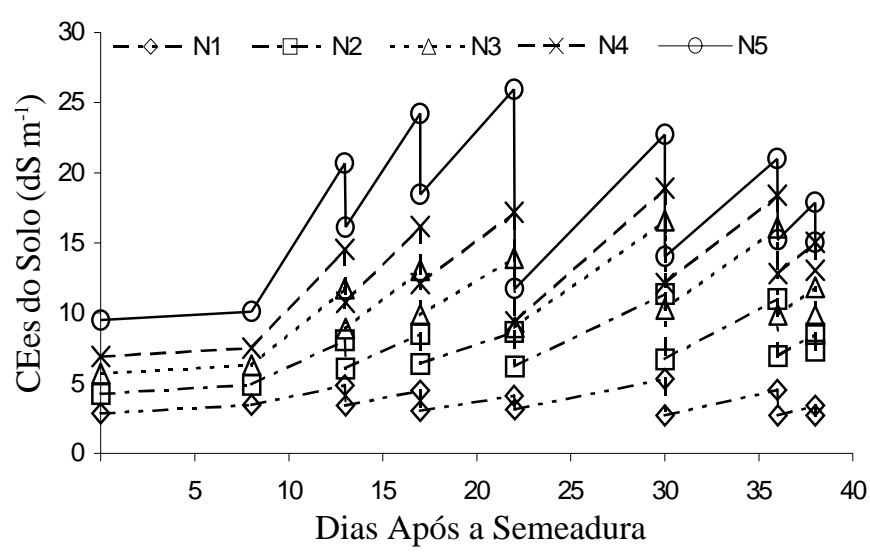

Figura 1. Curvas de salinidade do solo, obtidas pelo balanço e ajustadas pelos valores de salinidade medidas no final do ciclo da cultura 
As frações de lixiviação (FL) médias verificadas durante o período estudado, foram: 0,$14 ; 0,17 ; 0,19 ; 0,19$ e 0,23 , respectivamente, para os níveis de salinidade da água de irrigação, $\mathrm{N}_{1}$, $\mathrm{N}_{2}, \mathrm{~N}_{3}, \mathrm{~N}_{4}$ e $\mathrm{N}_{5}$. Por outro lado e se considerando cada período entre as drenagens, as FL médias foram: 0,15 (8 a $13 \mathrm{~d}$ ); 0,21 (13 a 17 d); 0,28 (17 a 22 d); 0,20 (22 a 30 d); 0,17 (30 a 36 d) e 0,17 (36 a 38 d). As FL são as responsáveis pela diminuição da CEes do solo após cada drenagem e no final do experimento (Figura 1).

A salinidade média do solo ao longo do experimento aumentou linearmente, 2,39 unidades, para o acréscimo de cada unidade de CE na água de irrigação; já no final do experimento observou-se efeito quadrático dos níveis de salinidade da água de irrigação sobre a salinidade do solo (Figura 2) e que, em termos numéricos, a diferença foi muito pequena, podendo-se considerar que as salinidades média e final do solo ao longo do experimento, são equiparáveis. Por outro lado, o comportamento quadrático observado na salinidade final também pode ser explicado pela variação da fração de lixiviação média $(0,14$, $0,17,0,19,0,19$ e 0,23$)$ entre os níveis $\left(\mathrm{N}_{1}, \mathrm{~N}_{2}, \mathrm{~N}_{3}, \mathrm{~N}_{4}\right.$ e $\mathrm{N}_{5}$, respectivamente), ocorrendo uma lixiviação maior com o aumento dos níveis de salinidade da água de irrigação.

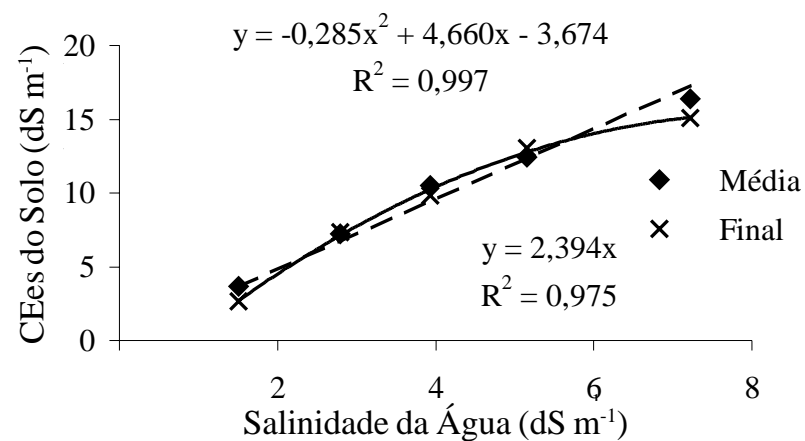

Figura 2. Salinidade média do solo durante e no final do ciclo da cultura, em função da salinidade da água aplicada
Procedendo-se aos cálculos da salinidade média do solo, esperada para as condições de equilíbrio, considerando-se uma única camada de solo e, conforme Rhoades et al. (1992), levando-se em conta quatro camadas com padrão de absorção radicular para método tradicional de irrigação, os valores dos fatores de concentração foram, respectivamente, 4,42 e 2,21, correspondentes a $84,9 \%$ acima e $7,53 \%$ abaixo do valor médio medido $(2,39)$ apresentado na Figura 2. A diminuição de 7,53\%, pode ser explicada pelas características de drenabilidade do solo utilizado no experimento e pela distribuição do sistema radicular, no vaso, que pode diferir do padrão de absorção, utilizado para os cálculos de 40,30, 20 e 10\% da profundidade efetiva das raízes; mesmo assim, a verificação de que quanto maior o nível de salinidade da água aplicada maior foi a salinidade resultante do solo (Figura 2), variando em função da lâmina de lixiviação, concorda com Rhoades et al. (1992) ao afirmarem que a salinidade do solo resultante da água de irrigação está relacionada principalmente ao seu teor de sais e à composição, assim como à quantidade da água aplicada e à fração de lixiviação realizada.

Frente à resposta das cultivares de melão em relação à salinidade da água de irrigação, a análise de variância mostrou que não houve efeito significativo entre as cultivares para os parâmetros altura de plantas (AP), área foliar (AF), fitomassa da parte aérea fresca (FFPA) e seca (FSPA), em todas as avaliações, exceto para 32 dias após semeadura (DAS), quando a AP da cultivar Gold mine se apresentou mais alta que a da AF646 (Tabela 3). Não se verificou, para qualquer parâmetro estudado, efeito significativo da interação cultivar versus salinidade, à exceção de altura de plantas aos 32 DAS.

A análise de regressão demonstrou que incrementos nos níveis de salinidade reduziram significativamente $(\mathrm{p}<0,01)$, para todas as épocas avaliadas, os parâmetros AP, AF, FFPA e FSPA (Tabela 3), concordando com os resultados obtidos por Shannon \& Francois (1978), Meiri et al. (1982) e Barros (1998).

Tabela 3. Valores médios* e estatística F para altura de plantas, área foliar, fitomassa da parte aérea fresca (FFPA) e seca (FSPA) das cultivares Gold mine e AF646, em relação aos níveis de salinidade da água de irrigação e cultivares em diversos dias após semeadura

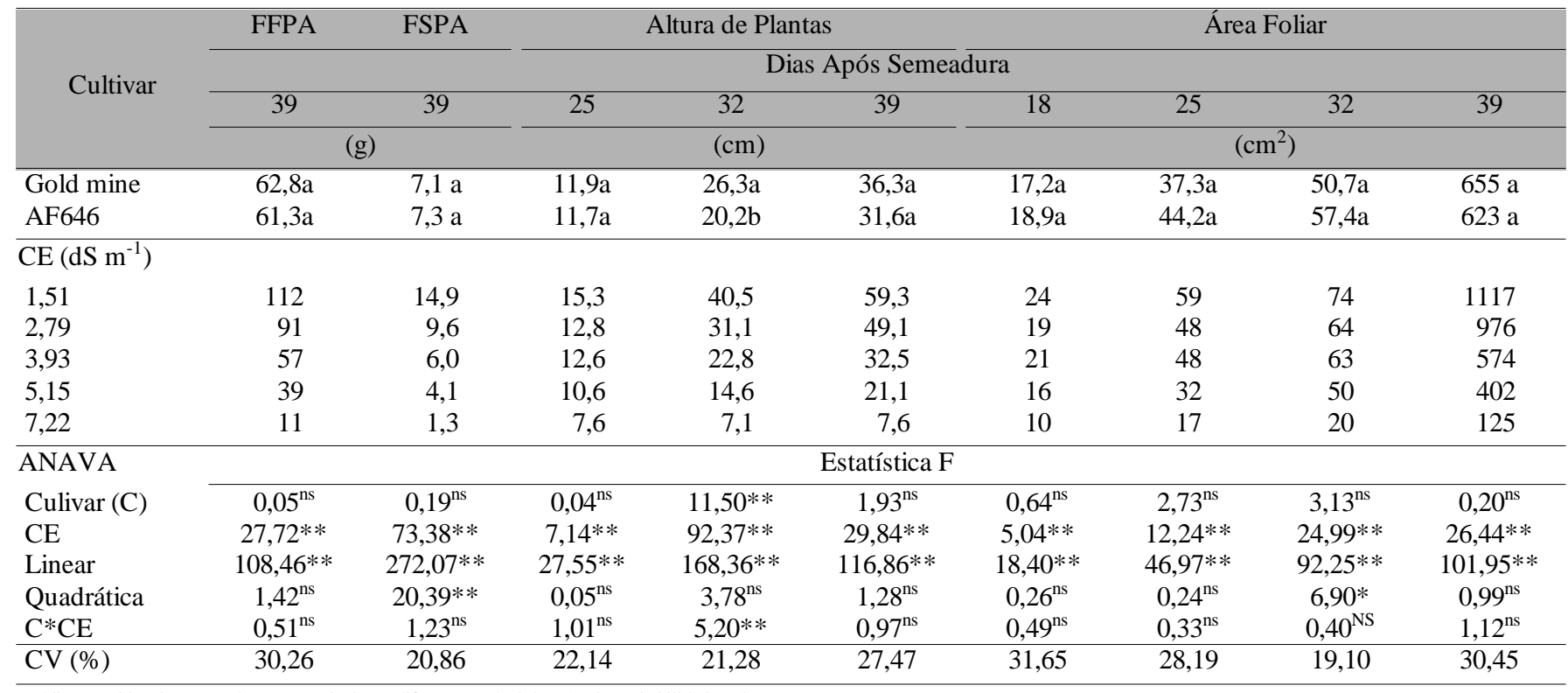

${ }^{+}$Médias seguidas de mesma letra na vertical não diferem ao nível de 0,05 de probabilidade pelo teste $\mathrm{F}$

ns, *,** Não significante ou significante a probabilidade de 0,05 e 0,01 , respectivamente 
A variação da $\mathrm{AP}$ e $\mathrm{AF}$ em relação aos níveis de salinidade da água de irrigação foi reduzida linearmente em todos os períodos avaliados, e apenas o parâmetro $\mathrm{AF}$ apresentou, também aos 32 DAS, efeito quadrático $(\mathrm{p}<0,05)$. Observa-se ainda que, à medida que o tempo de cultivo vai passando, aumenta a redução da $\mathrm{AP} \mathrm{e} \mathrm{AF}$ com o incremento na salinidade da água de irrigação (Tabela 3), comportamento este que pode ser atribuído ao aumento da salinidade do solo com o tempo de cultivo reduzindo, com isto, o potencial osmótico da solução do solo, diminuindo a disponibilidade de água às plantas e fazendo com que as culturas sofram uma redução progressiva no crescimento e produção, sempre que a concentração salina aumenta, concordando com Maas \& Hoffman (1977). Ressaltase um grande crescimento na $\mathrm{AF}$ em todos os níveis de salinidade observados no final do experimento.

Observa-se, na Figura 3, uma função quadrática da FSPA, e uma linear da FFPA e AF, com decréscimo dos parâmetros FFPA e AF, com o incremento da salinidade da água de irrigação, aos 39 DAS. Embora o efeito quadrático para a FSPA apresente coeficiente de determinação de 0,996 , o efeito linear, equação "y $=-15,482 x+112,06 "$, também mostra um coeficiente de determinação significativo a 0,01 e alto $\left(R^{2}=0,926\right)$ comprovando mais claramente a perda de rendimento pela salinidade da água de irrigação. $O$ incremento de $1 \mathrm{dS} \mathrm{m} \mathrm{m}^{-1}$ na salinidade da água de irrigação, reduziu linearmente a FFPA e a AF, em pouco mais de $16 \%$, e a FSPA em 15,5\% (Figura 3).

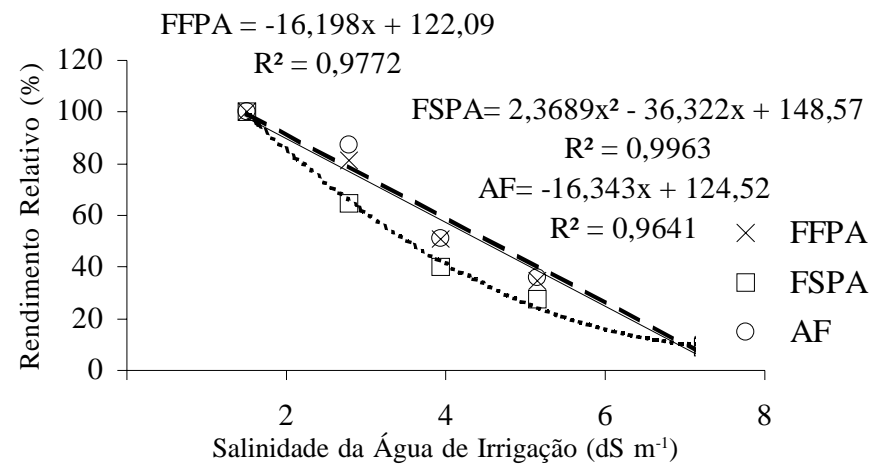

Figura 3. Comportamento no rendimento relativo da fitomassa da parte aérea fresca (FFPA) e seca (FSPA) e área foliar (AF) com o aumento da salinidade da água de irrigação

Estudando efeito da salinidade em melão com cultivo hidropônico, Franco et al. (1993), encontraram resultados semelhantes e em 1997, estudando os efeitos de três níveis de salinidade $\left(2,5,5,0\right.$ e $\left.7,5 \mathrm{dS} \mathrm{m}^{-1}\right)$ em 6 cultivares de melão, eles verificaram, aos $36 \mathrm{DAS}$, diminuição significativa entre a área foliar, variando entre 40 a $49 \%$, do tratamento mais salino em relação ao menos salino e também, nesse mesmo período (36 DAS) correlação entre a redução da área foliar e a redução da produção.

Os dados de rendimento relativo aos parâmetros AF e FSPA versus salinidade do solo apresentaram, aos 39 DAS, correlação parcial de 0,88 , verificando-se que, a partir de uma salinidade do solo de $3,7 \mathrm{dS} \mathrm{m}^{-1}$, o aumento de uma unidade na salinidade do solo reduziu, de forma linear, o rendimento relativo dos parâmetros AF e FSPA em, respectivamente, 7,44 e 7,18\%, nas cultivares estudadas (Figura 4). Como as duas retas se apresen- taram praticamente paralelas e próximas tanto a $\mathrm{AF}$ quanto a FSPA, fornecem a mesma avaliação. Esses resultados acrescentam à AF as conclusões de Nerson \& Paris (1984) que indicam a FSPA como o melhor parâmetro na seleção de cultivares de melão quanto a tolerância à salinidade, podendo ser utilizado desde o início do estágio vegetativo.

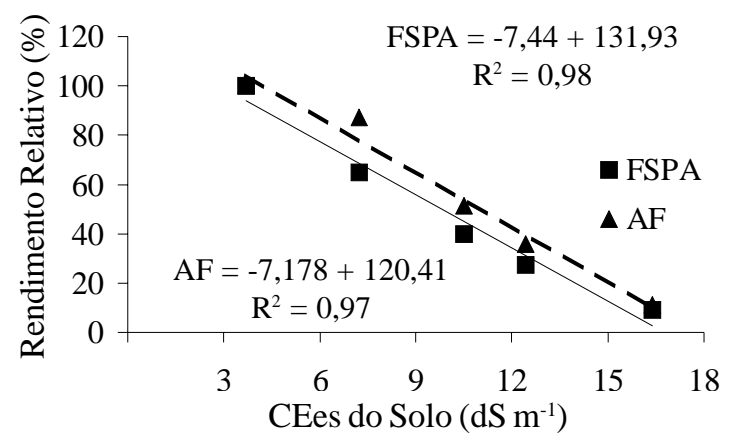

Figura 4. Rendimento relativo em fitomassa seca da parte aérea (FSPA) e área foliar (AF) para a cultura do melão, em relação à elevação do nível de salinidade do solo

Com os resultados apresentados através da Figura 4, não seria adequado utilizar-se a teoria de salinidade limiar (SL) e declínio de produção, conforme apresentada por Maas \& Hoffman (1977), pois já ocorreu redução imediatamente após o menor valor de salinidade do solo encontrada $\left(3,7 \mathrm{dS} \mathrm{m}^{-1}\right)$ que é bem superior aos valores de SL, para o melão, apresentado na literatura (Shannon \& François, $1978-1,3 \mathrm{dS} \mathrm{m}^{-1}$; Meiri et al., 1982 - 2,0 dS m${ }^{-1}$; Pizarro, 1990 - 2,2 dS m$~^{-1}$ ) ajustando-se, então, os resultados experimentais de AF e FSPA, percussores da Figura 4, para estimativa do parâmetro b, utilizando-se a SL, conforme Pizarro (1990), igual a 2,2 $\mathrm{dS} \mathrm{m}^{-1}$, na qual o rendimento relativo de FSPA ou da AF da cultura se comportaria estável, em platô de 100\%, obteve-se a Figura 5.

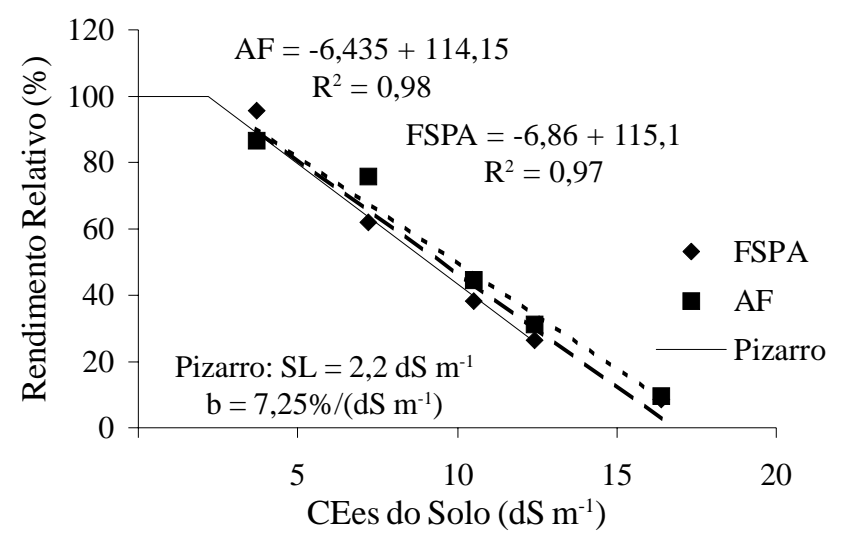

Figura 5. Comportamento do rendimento relativo da produção, segundo Pizarro (1990), e da fitomassa seca da parte aérea (FSPA) e área foliar (AF) do meloeiro, em função de níveis de salinidade do solo (assumindo $\mathrm{SL}=2,2 \mathrm{dS} \mathrm{m}^{-1}$ )

Na Figura 5, o rendimento relativo seria de $100 \%$ para valores de salinidade inferiores a $2,2 \mathrm{dS} \mathrm{m}^{-1}$ e sofreria uma redução de 6,43 e $6,86 \%$, respectivamente, na AF e FSPA, por unidade de acréscimo no nível de salinidade a partir desse limite, deixando de produzir, ou causando morte, a uma salinidade máxima de 
17,74 e $16,78 \mathrm{dS} \mathrm{m}^{-1}$. A esse respeito, os valores obtidos para redução e salinidade máxima tolerável pela cultura avaliada através da AF e FSPA, são levemente inferiores ao descrito por Pizarro (1990) para produção. Esta diferença se deve, provavelmente, às cultivares de melão testadas, e às condições divergentes de solo e clima nos locais onde foram realizados os experimentos pois, segundo Meiri et al. (1982), sob dois níveis de radiação em estufa, as cultivares de melão 'Galia e 'Top Mark' apresenta$\mathrm{ram}$, em média, $\mathrm{SL}=2,0 \mathrm{dS} \mathrm{m}{ }^{-1}$ e b $=14,3 \%$ e SL $=0,5 \mathrm{dS} \mathrm{m}^{-1} \mathrm{e}$ $\mathrm{b}=11,6 \%$, respectivamente, para as condições de sol e protegido com tela mostrando, assim, o efeito das condições climáticas nos parâmetros de tolerância da cultura à salinidade.

\section{CONCLUSÕES}

1. As cultivares Gold mine e AF646 apresentaram comportamento semelhante com o incremento da salinidade da água de irrigação, aos 39 dias após semeadura, apresentando reduções em todas as características avaliadas.

2. Para fitomassa fresca da parte aérea e área foliar, as reduções foram pouco mais de $16 \%$ por aumento unitário da condutividade elétrica, enquanto a fitomassa seca da parte aérea reduziu $15,5 \%$.

3. A salinidade média do solo, ao longo do experimento, aumentou linearmente 2,39 vezes em relação a salinidade da água de irrigação.

4. A produção de fitomassa tende a zero a uma salinidade no extrato de saturação do solo de $17 \mathrm{dS} \mathrm{m}^{-1}$.

5. A altura e área foliar das plantas tenderam a sofrer maior redução com a salinidade, do início para o final do crescimento.

\section{LITERATURA CITADA}

Barros, A.D. Germinação, vigor e desenvolvimento do meloeiro (Cucumis melo, L.) sob diferentes níveis de salinidade da água de irrigação. Campina Grande: UFPB, 1998. 78p. Dissertação Mestrado

Daker, A. A água na agricultura: Irrigação e drenagem. 6.ed. v.3. Rio de Janeiro: Freitas Bastos, 1984. 543p.

EMBRAPA - Empresa Brasileira de Pesquisa Agropecuária. Sistema brasileiro de classificação de solos. Rio de Janeiro: EMBRAPA/CNPS, 1999.412p.
Franco, J.A.; Esteban, C.; Rodriguez, C. Effects of salinity on various growth stages of muskmelon cv. Revigal. Journal of Horticultural Science, Ashford, v.68, n.6, p.899-904. 1993.

Franco, J.A.; Fernàndez, J.A.; Bañón, S. Relationship between the effects of salinity on seedling leaf area and fruit yield of six muskmelon cultivars. HortScience, Fort Collins. v.32, n.4, p.642-644. 1997.

Gomes, P.F. Curso de estatística experimental. São Paulo: Nobel, 1987.430p.

Hebron, D. Os problemas de salinização na irrigação. Recife: SUDENE (Divisão de Documentação), 1967. 17p.

Maas, E.V.; Hoffman, G.J. Crop salt tolerance assessment. Journal of the Irrigation and Drainage Division, ASCE, New York, v.103, n.IR2, p.115-134, 1977.

Medeiros, J.F. de. Manejo da água de irrigação salina em estufa cultivada com pimentão. Piracicaba: ESALQ, 1998. 152p. Tese Doutorado

Meiri, A.; Hoffman, G.; Shannon, M.; Poss, J. Salt tolerance of two muskmelon cultivars under two solar radiation levels. Journal of the American Society for Horticultural Science, Alexandria, v.107, p.1168-72, 1982.

Nerson, H.; Paris, H.S. Effects of salinity on germination, seedling growth, and yield of melons. Irrigation Science, New York, v.5, p.265-273, 1984.

Pizarro, F. Riegos localizados de alta frenquencia: goteo, microaspersión, exudación. 2.ed. Madrid: Mundi Prensa, 1990.459p.

Resh, H.M. Hydroponic food production: a definitive guidebook of soilless food-growing methods. 5ed. Santa Barbara: Woodbridge Press Publishing Company. 1995. 527p.

Rhoades, J.D.; Kandiah, A.; Mashali, A.M. The use of saline waters for crop production. Rome: FAO, 1992. 133 p. Irrigation and Drainage Paper, 48

Rhoades, J.D.; Loveday, J. Salinity in irrigated agriculture. In: Stewart, D.R.; Nielsen, D.R. (eds.). Irrigation of agricultural crops. Madison: ASA/CSSA/SSSA, 1990. p.1089-1142. Agronomy, 30

Richards, L.A. (ed.) Diagnosis and improvement of saline and alkali soils. Washington: United States Department of Agriculture, 1954. 160 p. USDA, Agriculture Handbook, 60

Shannon, M.; Francois, L. Salt tolerance of three muskmelon cultivars. Journal of the American Society for Horticultural Science, Alexandria, v.103, p.127-30, 1978. 